\title{
A ATIVIDADE HUMANA, SIMULTANEAMENTE INTELECTUAL E VITAL: ESCLARECIMENTOS COMPLEMENTARES DE PIERRE PASTRÉ E YVES SCHWARTZ
}

\author{
HUMAN ACTIVITY, BOTH INTELLECTUAL AND VITAL: COMPLEMENTARY APPROACHES \\ OF PIERRE PASTRÉ AND YVES SCHWARTZ
}

Louis Durrive $^{1}$

Resumo Toda situação de trabalho se presta a uma dupla abordagem. É o local onde se realiza uma tarefa, pensada anteriormente e provocadora de uma intensa atividade intelectual pelo trabalhador. Mas é igualmente um momento único da vida, com suas arbitragens. Nesse caso, a tarefa não é mais vista como primeira, ela entra no 'debate de normas' que caracteriza a atividade do trabalhador sob o ângulo vital, aquele das escolhas que um ser humano não cessa de fazer. Entendemos que essas duas perspectivas correspondem, respectivamente, à de Pierre Pastré e à de Yves Schwartz. Elas se completam e enriquecem a análise: seu entrecruzamento confere, notadamente, um destaque inédito à questão das competências.

Palavras-chave experiência do trabalho; entrevista; competência; saber-fazer; meio de trabalho; formação alternada.
Abstract There can be a dual approach to every work situation. It is the place where a task is done, one which has been planned previously and which leads the worker to an intense intellectual activity. But it is also a unique moment in life, with its arbitrations. In this case, the task is no longer seen as the first. In fact, it enters the realms of the debate of rules that characterize the worker's activity from the critical perspective, the one of the choices a human being never ceases making. We believe these two perspectives correspond to Pierre Pastré and Yves Schwartz's views, respectively. They complement and enrich the analysis: the intersection between them gives rise, notably, to an unprecedented emphasis on the issue of skills.

Keywords work experience; interview; skills; knowhow; working environment; alternated training. 
“Toda atividade de trabalho é sempre, em algum grau, de um lado, descritível como um protocolo experimental e, de outro, experiência e encontro. Isto nos parece ser o início de todo olhar ergológico sobre ela" (Schwartz, 2000 b, p. 485). Uma situação produtiva pode ser abordada de duas perspectivas diferentes. Seguindo uma primeira abordagem, consideraremos a tarefa num primeiro plano. Ela é definida anteriormente e o trabalhador é convocado a colocá-la em prática. Com os seus colegas, ele realizará o que é preciso e desenvolverá uma atividade intelectual buscando maneiras de ser eficaz. A segunda perspectiva consiste em visualizar essa situação antes de tudo como um momento de vida. Algumas pessoas estão lá e se ocupam; a cena é composta por uma sucessão de eventos. A tarefa em questão é levada em conta, mas ela é conduzida a partir de uma história local, segundo as apostas e as urgências de diferentes protagonistas. Insistindo sobre os encontros do momento presente, enfatizamos a atividade vital, a vida feita de escolhas. Nenhuma das duas perspectivas apresentadas aqui reduz o trabalho à aplicação de um procedimento: trabalhar é pensar, e também é viver. Levantamos aqui a hipótese de que as abordagens de Pierre Pastré e de Yves Schwartz se complementam. As duas compartilham um ponto de vista antropológico sobre o processo de conhecer. Entretanto, elas se distinguem na medida em que, em relação ao homem no trabalho, uma aborda a atividade sob o aspecto vital, e a outra privilegia seu aspecto intelectual. São duas visões complementares para melhor compreender a atividade humana, que não separa jamais a "relação entre" e a "relação com"2 bem como as competências no trabalho, o que a nossos olhos é a aposta na formação alternada.

\section{Uma apresentação resumida da abordagem ergológica}

A concepção de homem no mundo é o ponto de partida da reflexão do filósofo Yves Schwartz. Herdeiro de outro filósofo, Georges Canguilhem, ele raciocina a partir do 'meio de vida', entendido num sentido preciso.

Como ser vivo, o homem não escapa da lei geral dos seres vivos. $\mathrm{O}$ meio próprio do homem é o meio da sua percepção, ou seja, o campo da sua experiência pragmática onde suas ações, orientadas e regradas pelos valores inerentes às tendências, recortam objetos qualificados. $\mathrm{O}$ homem relaciona os objetos qualificados a outros objetos, e todos os objetos em relação a ele, de tal forma que o meio no qual se supõe que ele vá reagir se acha originalmente centrado nele (Canguilhem, 1992a).

O meio de vida designa, no caso presente, não o ambiente natural ou as condições sociais que possamos analisar independentemente dos pontos de vista individuais, mas o mundo tal como cada um tende a reconstruir em torno de si, a fim de viver como ser singular. Entretanto, esta característica 
do ser vivo não é suficiente para dar conta da atividade especificamente humana. O que caracteriza o homem é, na verdade, a capacidade de se mover dentro de um universo de normas. O termo 'norma', em latim, significa esquadro, aquilo que se pretende corrigir, ou retificar, algo que já está posto. A precisão é importante, porque se a transgressão ocorre antes, como escrevia Canguilhem (1999), isto quer dizer que a norma vem após a transgressão. Quando ações são realizadas, a norma vem, num segundo momento, fixar os limites do que é lícito e do que é interdito. Entretanto, a norma, ao contrário, se apresenta como anterior, ela se posiciona no início do agir. De onde vem esse paradoxo? Na realidade, a norma não tem autoridade de uma lei natural. De fato, ela vem depois, ela decorre de uma escolha, mas para ganhar força e funcionar de maneira eficiente, ela necessita ser apreendida como inicial e permanente.

Uma norma é consequentemente a expressão daquilo que uma instância avalia como devendo ser. Esta instância pode ser exterior ao indivíduo: são as normas exógenas, aquilo que exigimos de cada um, aquilo que procuramos lhe impor. Mas esta instância pode ser também o próprio indivíduo, porque cada um tende a definir suas próprias normas para agir, cada um tenta estar na origem das exigências que o governam (normas endógenas). Ninguém se conforma com a imposição do meio, como se fosse um conteúdo ajustado ao que apenas lhe cabe melhorar. O homem não se deixa totalmente comandar de fora, ele está, ao contrário, numa relação polêmica com o mundo das normas nas quais se encontra. Isto não significa que esteja sistematicamente em oposição ao meio, contra o que se espera dele, porque a saúde significa vida em flexão, vida com capacidade própria de ajustamento. É em nome da saúde precisamente que o indivíduo não renuncia a viver sendo ele próprio o centro de referência. “Todo homem quer ser sujeito de suas normas" (Canguilhem, 1947, p. 136).

Assim, cada vez que ele é convocado a agir, o ser humano é confrontado com o que exigem dele e com o que ele exige de si mesmo. Ele entra num debate de normas (a palavra 'debate' aqui utilizada no sentido de Canguilhem ao descrever a situação do ser vivo em geral): “Entre o ser vivo e o seu meio, a relação se estabelece como um debate (...) onde o ser vivo aporta suas próprias normas de apreciação das situações, onde ele domina o meio e se acomoda a ele" (Canguilhem, 1992a, p. 147).

O debate de normas não pode, entretanto, ficar muito tempo em suspenso. É necessário decidir, arbitrar em um dado momento. Com efeito, agir nos obriga a escolher: impossível passar aos atos mantendo duas hipóteses. É necessário adotar uma só maneira de fazer qualquer coisa e vem daí o posicionamento singular de agir. Cada um tende a renormalizar, a fazer sua a norma que antecipa e ajusta seu agir, a fim de se manter - mesmo que seja pouco - na origem do 'uso de si', mesmo se conformando com a demanda que lhe é posta. 
A partir de Canguilhem, falaremos do exercício da normatividade: o ser humano responde às solicitações do seu meio - o que os outros em geral lhe pedem para fazer - obedecendo à norma sem renunciar a investir nela subjetivamente. Daí vem a distância suscitada pela regra, mas que vai retornar a ela mesma: uma dinâmica toma forma que faz "quebrar as normas", renovando-as por mudanças sucessivas, por força da invenção subjetiva.

Normativo se opõe à normal: é normal tudo o que é conforme uma norma preexistente, é normativo tudo o que institui por si mesmo uma norma original, não identificada antecipadamente. Distinguimos de fato a norma como média estatística, quer dizer como constante comum a um grupo de indivíduos, ou a diversos estados sucessivos de uma existência individual, e a norma como inovação dinâmica, quer dizer como capacidade de ultrapassar todo constante preestabelecido, individual ou coletivo (Della Valle, 2007, p. 140).

Fazer algo permite simultaneamente construir a si mesmo. Nossas tomadas de posição no agir se encadeiam e nos produzem. Finalmente, na perspectiva de Canguilhem, a individualidade pode ser entendida como a maneira própria de cada um se confrontar com as normas.

O que precede mostra que a abordagem ergológica se funda num ponto de vista antropológico. Interrogar-se sobre a atividade suscita questões fundamentais: o que é um homem no mundo e, mais radicalmente, o que é viver? Com Alain Wisner (1995), a ergonomia de origem francesa colocou em evidência no trabalho o que chamamos a distância entre o prescrito e o real. É uma primeira etapa para compreender a atividade como um debate de normas. Mas para ir mais além, convém reconhecer duas coisas. Inicialmente, reconhecer que "viver, é irradiar" (Canguilhem, 1992a, p. 147) ou, em outros termos, é organizar o meio em função de si como centro: centro de avaliação, de valorização; centro de decisão concernente ao seu próprio agir. Em seguida, e isto é uma especificidade dos seres humanos, reconhecer que viver é se confrontar com um mundo de normas.

O projeto de uma norma é antecipar o agir, enquadrá-lo: é o que deve ser. Os elementos de uma dialética entram em ação: eu ajo em função de uma provocação ou mais diretamente de uma solicitação do meio, é o que exprime a norma; mas ajo buscando obstinadamente ficar no centro da decisão de agir. Eu não sou um autômato, eu tenho a ambição de existir agindo, de conservar minha singularidade. Norma, renormalização: uma precede a outra, à imagem do pé direito que ultrapassa o pé esquerdo e reciprocamente. A norma pretende adiantar ou preceder o que se vai fazer, mas a renormalização é também uma forma de antecipação, pois ela vai além do que está previsto, pensado antecipadamente pela norma. Compreende-se 
melhor de agora em diante 'a distância entre o prescrito e o real' como uma das manifestações da dialética que caracteriza a atividade humana.

É necessário, no entanto, ser mais preciso porque a relação entre prescrito e real se inscreve na atividade de trabalho, embora até aqui tenhamos evocado mais amplamente a atividade humana incluindo a vida cotidiana. O homem, dissemos, está em diálogo permanente com seu meio: isto o provoca, o incita a tomar posição, a escapar à neutralidade e à indiferença a fim de viver com saúde. Mas a pressão do meio pode tornar-se mais forte: somos então exigidos a fazer uso de nós mesmos, a participar ativamente a serviço de uns pelos outros. Entramos então na esfera do trabalho. Antes mesmo de se engajar no fazer, cada um deve se confrontar com normas de alguma maneira enrijecidas: “as normas antecedentes" (Schwartz, 2000b). Enrijecidas na medida em que elas são investidas por relações sociais, por relações de poder. Elas visam a enquadrar as atividades humanas e são produzidas pela história dos grupos e das sociedades que buscam instituir a vida coletiva.

As normas antecedentes têm duas características importantes (Schwartz e Durrive, 2009). A primeira, como seu nome indica, se refere ao fato de se posicionarem antes de começar o trabalho que elas tornam possível. Isto significa que elas são duradouras no ambiente, enquanto as normas de vida cotidiana são mais difusas, incluídas, até mesmo, nos efeitos das normas antecedentes. Além disso, elas se instalam como se estivessem naturalmente na origem da ordem, e é isto que lhes dá prestígio. Porque tal é o problema da norma: encontrar fontes de autoridade. Na vida comum, na educação, por exemplo, a norma impõe sua autoridade rejeitando outras formas do fazer. Quando ela se manifesta no mundo do trabalho, a norma se aproveita de relações de subordinação para afirmar sua prioridade. Mas, o processo é sempre o mesmo; a norma necessita de "homens normativos" (Canguilhem, 1999) para ser atualizada, entrar na história - justamente porque ela não é equivalente a uma lei natural.

A segunda característica das normas antecedentes é a de serem anônimas. Em outras palavras, elas não levam em conta a singularidade de quem se prepara para agir. Indiferentes ao ator e à sua história, elas se apresentam como neutras - mas não atemporais, pois reclamam anterioridade. As normas antecedentes contradizem de certa forma a atividade humana, ponto por ponto, e é assim que elas a enquadram e a tornam possível.

De fato, a atividade é sempre ancorada no presente: não se pode agir em vários lugares ao mesmo tempo nem em vários tempos. Por outro lado, a atividade reenvia forçadamente a um alguém preciso, uma pessoa determinada, um "corpo-si" singular (Schwartz, 2000b): impossível agir por meio de outro, por procuração. A norma antecedente e anônima vai, pelo trabalho, 
se repetir, estando ao mesmo tempo atualizada e 'desneutralizada' (investida por alguém que põe fim ao anonimato). As normas antecedentes estão presentes antes do trabalhador, e ao mesmo tempo elas não existem senão a partir dele, graças à sua atualização. Sem um trabalhador concreto, nada acontece. A norma necessita de um homem normativo, capaz de renormalização.

Ao falar da história humana, Yves Schwartz menciona a "invenção da desaderência" (Schwartz e Durrive, 2009) para qualificar o extraordinário salto qualitativo que corresponde à emergência do pensamento, da cultura, do mundo das normas. Uma invenção que é "capacidade enigmática e prodigiosa de produzir um pensamento, que pode nomear, avaliar, agir sobre o presente, a partir de configurações conceituais que antecipam in absentia". (Schwartz, 2009, p. 15).

A desaderência é a distância que o espírito humano é capaz de tomar em relação ao que acontece, às circunstâncias nas quais ele se acha ancorado em um dado momento. A desaderência se manifesta antes de tudo pela linguagem. A linguagem a serviço da atividade na vida comum, com as palavras que constroem outras formas de distância relativa à instantaneidade do ato, tal como o gesto industrioso e a técnica. A linguagem disciplinada igualmente, que se coloca a serviço do conhecimento, do universo de conceitos, da ciência.

A desaderência deu aos homens o poder de intervenção no mundo, criando uma separação nítida das populações animais. No entanto, a atividade humana fica enraizada no aqui e agora. Viver e trabalhar faz parte da experiência de viver, é ir ao encontro do presente, que Yves Schwartz chama de "aderência". Quem decide fazer algo deve enfrentar as provocações do momento presente. De acordo com a situação, o meio a viver opõe resistências ou oferece apoios. A atividade humana aparece, assim, como a gestão indefinidamente renovada e sempre problemática de uma tensão entre o local e o atual, e entre os diversos graus de distância, de antecipação. Em outras palavras, a atividade está em tensão entre o que está previsto pelos procedimentos, graças, de um lado, ao pensado em desaderência e, de outro, "à infidelidade do meio" (Canguilhem, 1999), às surpresas dos acontecimentos, ao "desafio da aderência" (Schwartz, 2009).

Poderíamos considerar que é desnecessário falar de algo evidente, como o fato de o trabalho ser ancorado no tempo presente. Seria ignorar a tentação sempre forte de modelizar a situação de produção até pretender ter tudo previsto. Desloca-se abusivamente o prestígio do conceito do modo que ele se desenvolve legitimamente no estudo dos fenômenos naturais para a atividade humana e social - uma tentação que cresce, atualmente, com o desenvolvimento das tecnologias da informação e da comunicação. Essa tendência, segundo Yves Schwartz, vem mutilar a atividade: 
(...) pensar somente em desaderência a vida social, o trabalho - e utilizar assim o benefício do prestígio de um saber científico - é de alguma maneira "mecanizar" a vida humana, considerá-la como essencialmente analisável no polo da antecipação, deixando o resto como residual; é desconhecer o seu permanente enfrentamento aos desafios da aderência, os quais sempre podem ser definidos como debates mais ou menos legítimos com as normas (Schwartz, 2009, p. 21).

O duplo conceito de aderência/desaderência caracteriza a abordagem ergológica da atividade. Retomamos em filigrana a dialética da vida e do conceito de Georges Canguilhem. Toda renormalização é um misto efetuado por um ser singular entre o pré-pensado, o pré-tratado pela desaderência no campo conceitual, e pelo que o presente da vida humana obriga a pensar, a fazer. E se podemos falar de enigma a respeito da vida humana, é em referência a essa dialética do conceito e da vida. Somente se apreciará realmente a força do conceito, da desaderência, da norma, tomando a medida do imperativo da aderência na vida. Em outras palavras, na análise de uma situação produtiva, não se pode deixar de lado o ponto de vista do trabalhador porque somente ele vive a tensão entre os dois polos, entre o que antecipa e o que não antecipa.

A atividade, como dissemos, não se apreende a partir somente da desaderência, por exemplo, somente pela organização do trabalho, das tarefas, dos procedimentos. Além disso, examinar como observador externo o momento presente do trabalho não é suficiente: o ponto de vista de quem trabalha é incontornável. Esse imperativo merece ser aprofundado porque permite melhor se aproximar do conteúdo do debate de normas.

Uma norma corresponde a uma maneira de fazer, ligada consequentemente a um saber. Diversas maneiras de colocá-la em prática são possíveis, e a renormalização é um compromisso efetuado por uma pessoa singular. Mas dizer isso é insuficiente: viver não é compor um programa de possibilidades, que poderíamos repertoriar, e do qual teríamos um dia o controle estatístico! Viver é escolher, decidir entre muitas maneiras de se fazer certas coisas, em referência a um mundo de valores. Isto porque a norma tem duas origens: os saberes e os valores. Uma norma é uma maneira de fazer 'privilegiada', associada a um valor. Ela jamais é neutra para aquele que age, mesmo se a desaderência reivindica a neutralidade, a autonomia em relação ao viver que é situado e datado. Dessa forma, o agir humano se inscreve num triângulo com os saberes e os valores: há o debate de normas e, como resultado, a renormalização, na medida em que o que se conhece da situação a gerir (os saberes do métier, da organização) se entrecruza com o que se sabe especificamente a respeito dessa situação (os saberes investidos na atividade). Mas esse debate é reiterado no confronto entre o que tem valor para 
os outros e o que tem valor para uma determinada pessoa em um momento dado. "A atividade é uma tentativa permanente de colocar em sinergia todos os debates de normas que são solicitados ao agir. Essa sinergia cria alguma coisa como uma experiência". ${ }^{3}$

O trabalhador leva em conta consígnias, analisa uma situação, adota uma estratégia, segue um raciocínio. Seu trabalho se interpreta no campo dos conceitos como uma sequência de atos pensados, o resultado de um esforço de conhecer. Entretanto, a dimensão conceitual do agir se articula necessariamente a uma dimensão axiológica. O esforço de conhecer é solidário ao esforço de viver. Dito de outra forma, a desaderência é incapaz de levar em conta sozinha a atividade humana: esta atividade é unida a uma vida em aderência, ela está em relação com o mundo dos valores. A atividade intelectual é, desse modo, uma atividade vital.

Uma entrevista do tipo ergológico sobre a atividade de trabalho dá, assim, certa clareza sobre os debates de normas de uma pessoa engajada em situação de produção. Com ela, reconstituiremos o fio de suas arbitragens sucessivas. Em nenhum caso estas podem manifestar uma singularidade absoluta, existem estabilidades no agir individual: é o sentido mesmo da produção de normas, quer elas sejam exógenas, endógenas, ou resultado de uma renormalização. Ao mesmo tempo, essas arbitragens sucessivas vão evidenciar uma singularidade parcial, irredutível - e isto é devido em grande medida à atividade normativa da vida, às polarizações em valores positivos e negativos.

A atividade humana no trabalho não é a simples aplicação de saberes já constituídos: no curso da atividade, outros saberes se produzem. Ora, esses saberes em aderência são presos a um mundo de valores. Dar visibilidade aos saberes investidos na atividade supõe considerar essas polarizações: não desconectar no curso da análise as duas desaderências, dar tempo para a formalização a fim de distingui-las respeitando as "dramáticas do uso de si". ${ }^{4}$ Porque existem duas desaderências: a desaderência conceitual, ilustrada pelas normas antecedentes; e a desaderência axiológica, que recobre o mundo de valores sem dimensão, aqueles que (como a desaderência conceitual) nos precedem e nos ultrapassam - porque não inventamos os valores, nós os retrabalhamos e os redefinimos na atividade.

Cabe aqui uma observação importante. Chamando atenção para os fins próprios a cada um no seu agir individual, não consideramos que todos os pontos de vista são equivalentes. Cada um tem suas razões para agir, mas não tem necessariamente razão. Interpretar como relativismo a abordagem que liga os conceitos e os valores será um grave contrassenso. Trata-se de compreender que o esforço de conhecer, procurando a objetividade, portanto, uma forma de verdade, não deve ocultar o esforço de viver de que é solidário o debate de normas num mundo de valores. Viver obriga a escolher, 
no sentido do inédito: não o inédito dos valores em si, porque ninguém os criou, mas o inédito da sua confrontação num ser singular inscrito num momento da história. Cada vez que ignoramos o surgimento do inédito em nome de uma vontade de racionalizar as escolhas humanas, corremos o risco de olhar o homem como um "ser vivo simplificado" (Canguilhem, 1947, p. 122).

As hipóteses da ergologia tais como expusemos até aqui conduzem Yves Schwartz a propor uma abordagem original de diálogo de saberes - os saberes acadêmicos e os que são produzidos pela atividade. Ele descreve estes últimos da seguinte maneira:

São saberes em aderência, em capilaridade com a gestão de todas as situações de trabalho, elas mesmas consideradas nas trajetórias individuais e coletivas singulares, contrariamente aos saberes acadêmicos, formais, que são desinvestidos, quer dizer, que podem ser definidos e religados com outros conceitos, independentemente das situações particulares (Schwartz, 2004, p. 20).

Entretanto, são dois tipos de saberes que podem se fecundar mutuamente. Mas os saberes investidos não são uniformes: alguns estão disponíveis para se colocar em palavras, apresentam continuidades aceitáveis com os conceitos tais como são ensinados. Outros restam profundamente incorporados, provisória ou definitivamente inconscientes. "Investidos mostra bem a dificuldade desse continuum da experiência entre o que, de certa maneira, não será jamais inteiramente colocado em linguagem, e o que, na experiência dos protagonistas do trabalho, está já no protocolo" (Schwartz, 2004, p. 20, grifo do autor).

Nós transformamos continuamente o mundo pela atividade humana. Isto produz certo tipo de saber, de construções híbridas, mais ou menos em aderência, portanto ligadas a valores reconcebidos localmente, e mais ou menos em desaderência, quer dizer, próximos de uma elaboração conceitual. Yves Schwartz os diferencia dos conhecimentos linearmente organizados ou saberes constituídos como duas formas de recursos intelectuais distintos, mas comensuráveis. Ele os situa em dois polos diferentes, o termo polo significando que encontramos aqui tendências, não recortes nítidos. Não se trata de caricaturar uma oposição entre planejadores, de um lado, e executores, de outro. As mesmas pessoas podem estar no primeiro polo, aquele dos saberes constituídos, porque elas são trabalhadoras, se posicionando no segundo polo, no ângulo de sua atividade.

O diálogo desses dois polos não tem nada de evidente. O polo 1, apoiado no prestígio do conceito científico, pode se contentar construindo saberes sob a forma de modelizações neutralizantes e continuar a ignorar o retrabalho desses saberes na atividade. O polo 2, considerado nas urgências da ação, não tem necessariamente a disponibilidade para a formalização, tanto 
mais que a manutenção de certa opacidade de saberes no trabalho pode ser uma verdadeira aposta, de onde a abordagem ergológica preconiza um terceiro polo, capaz de provocar a interfecundação dos saberes. Falaremos de um estado de espírito ou ainda de uma postura específica a sustentar (via uma animação ou uma formação ad hoc): impossível de fato haver o encontro entre os dois primeiros polos sem que haja uma espera mínima de cooperação, um tipo de desconforto que incite a ir para o outro polo.

Duas condições possíveis: a primeira é de ordem epistemológica porque é uma questão de produção original de saberes, implicando a preocupação de ir à procura de novos recursos; a segunda é de ordem ética, porque uma escuta real passa pela autêntica convicção do inédito na fala do outro, uma vontade de saber, um certo olhar sobre seu semelhante. No fundo, cada um deve "estar disponível para redesenhar sua parte de ignorância sempre renovada, sem perder a ambição de saber" (Schwartz, 2000a, p. 126). Modéstia e aceitação do não saber parcial, de uma parte; rigor e exigência de saber, de outra.

O terceiro polo é o provocador do encontro entre os polos 1 e 2, mas igualmente o beneficiário do trabalho cooperativo. Ele produz saberes novos, que são também, na perspectiva de uma conduta de mudança, verdadeiras reservas de alternativas, porque a atividade transborda novas ideias produzidas no debate de normas. Juntos, chegamos ao cerne da atividade humana aprendendo a desdobrar/ampliar o triângulo: agir - valores - saberes. Criamos então um lugar central entre dois imperativos, o de pensar pelos conceitos e o de tratar as urgências.

Yves Schwartz designa o agenciamento assim constituído de "dispositivo dinâmico a três polos". A palavra dinâmico faz referência a tudo que pode ser gerado de tais matrizes, em particular, a visibilidade das renormalizações; a tomada de consciência provocada pela colocação em palavras; o exercício formador que consiste em retorcer e retrabalhar conceitos; o retrabalho dos valores humanos, sociais, coletivos; a renovação dos saberes formais e disciplinares; a transformação dos meios de vida...

\section{Complementaridades entre as duas abordagens: ergologia e didática profissional}

A polaridade aderência/desaderência permite situar a complementaridade de duas abordagens da atividade, a perspectiva ergológica e a didática profissional. Sem dúvida é necessário, para compreender isso, retomar a relação entre conceito e vida. São dois termos seguidamente convocados na história do pensamento, seja por serem opostos, seja, ao contrário, por serem confundidos. A posição de Georges Canguilhem (1994) permite ir além dessa antítese, distinguindo o conceito e a vida sem jamais separá-los. 
O conceito na verdade é um instrumento a serviço do conhecimento, ele se beneficia de uma exterioridade em relação à vida. Sobre isso, Yves Schwartz (2009), como dissemos, evoca a "invenção da desaderência", um prodigioso salto qualitativo e decisivo na história dos homens. Mas o conceito é igualmente, na vida, um instrumento a serviço da vida: ele prolonga o esforço do ser humano para dominar seu meio, organizando-o segundo seus valores de ser vivo. Conhecer é uma modalidade de viver. Conceito e vida formam assim uma unidade dialética. O conceito se distingue da vida, é o que faz da perspectiva científica uma perspectiva original. Ao mesmo tempo, o conceito permanece ligado à vida, ele não se desprende: de fato é em relação a um problema de vida que o conhecimento faz sentido. No ato de conhecer, que recobre a perspectiva científica em todas suas variabilidades, o homem continua a afirmar valores vitais. Segundo Le Blanc (2002, p. 266), para Canguilhem, “a identificação do conceito e da vida (perspectiva biológica) deve ser admitida ao mesmo tempo que a atividade propriamente conceitual do conhecimento da vida".

É nessa mesma relação dialética que é preciso encontrar a dupla aderência/desaderência. A linguagem está em tensão entre os dois polos do viver humano: de um lado, o que antecipa graças à desaderência e, de outro, o que não antecipa, porque atado à própria vida, cheia de aderência. A linguagem serve ao mesmo tempo ao esforço de conhecer, por exemplo, através da padronização da atividade industriosa, e serve simultaneamente ao esforço de viver, acompanhando as renormalizações nos atos de trabalho os mais microscópicos.

Yves Schwartz fala da "má" desaderência quando a linguagem é, pelos jogos de relações de poder, retirada dessa tensão original entre atividade intelectual e atividade vital. Por exemplo, seria um desvio abusivo da linguagem deixar crer que tal organização, tal categorização ou codificação 'faz leis' como o faria uma lei natural: não seria uma escolha, seria 'natural'. A usurpação aqui vem de confundir os registros de conceitualização (no nível epistemológico), o das ciências da natureza, em que os objetos estudados não renormalizam, com o que é próprio da atividade humana. Ao contrário, uma boa desaderência, quer dizer, um uso sadio dos conceitos, cada vez que se trata de pensar a atividade dos homens, consiste em verificar que a modelização proposta, e que neutraliza os debates de normas por uma distância dos valores estabelecidos localmente, se preocupa regularmente com as renormalizações.

Um dever, uma ascese ou ainda uma disciplina do espírito: Schwartz (2000a) forjou a dupla disciplina epistêmica/disciplina ergológica para descrever o movimento dialético entre, de um lado, o que visa a encontrar uma arquitetura conceitual cada vez que se fala da atividade humana; 5 de outro, o que busca se instruir o mais próximo do debate de normas. A nosso ver, 
a complementaridade entre a dialética profissional e a ergologia reúne a dupla preocupação de compreender as regularidades incorporadas na atividade (excentrement: 6 da vida para o conceito, antecipação das situações e do meio pelo conceito) e de levar em conta as singularidades que fazem da atividade um momento da história (recentrement: do conceito para a vida, busca do ser humano por ser o centro de novas normas de vida).

A perspectiva ergológica e a didática profissional têm uma referência em comum, a ergonomia da atividade. Para muitos pesquisadores, evidenciar a distância persistente entre o trabalho prescrito e o trabalho real renovou profundamente, na segunda metade do século XX, questões fundamentais, tais como as relações entre a linguagem, o pensamento e a ação, as condições de produção de um saber sobre o ser humano, a existência mesmo de um objeto para as ciências humanas (Schwartz, 2005). De fato, o modelo taylorista-fordista de separação entre concepção e execução reconduziu o fazer industrioso a uma aplicação mecânica de saberes teóricos. A partir daí, a separação rígida, comumente admitida, entre o que é da ordem do conhe-cimento e o que é da ordem da ação é recolocada em debate.

Quando Gérard Vergnaud (1996, p. 291) escreve que é preciso "renunciar à idéia positivista de uma língua que expressaria todos os objetos do universo, e de maneira unívoca", ele conclui: "nós somos condenados à aproximação". O conhecimento na sua forma predicativa só pode parcialmente pretender encontrar o conhecimento na sua forma operatória. A ação mobiliza mais saberes do que a teoria pode dar conta.

Do lado do trabalho, isso significa que o operador não espera do prescrito uma exposição integral do que ele precisa fazer. Se o trabalhador não aplicar cegamente o prescrito, mas necessariamente pensar, se o controle total das variabilidades do meio pela organização - uma forma de antecipação que se apoia sobre a linguagem é impossível -, significa dizer que não se pode prescindir da intervenção humana, portanto da reflexão de quem trabalha. É necessário alguém para satisfazer as insuficiências da antecipação, gerir os 'furos' de normas, segundo a expressão de Yves Schwartz (Schwartz e Durrive, 2003).

A abordagem inaugurada por Pierre Pastré entende o trabalho como uma atividade intelectual: a didática profissional nasceu da preocupação de analisar a aprendizagem que se faz no exercício da atividade profissional: aprende-se a fazê-la, mas se aprende também fazendo. “É preciso operar uma análise interna da atividade para perceber particularmente aquilo que ela comporta de conceitualização" (Pastré, 2006, p. 109). Pensar na ação é uma necessidade. A situação de trabalho é organizada antecipadamente pela prescrição, o modo operatório é pensado pelos outros e toda uma instrumentalização acompanha o homem no trabalho. Para esse último, são todos preciosos recursos. No entanto, é importante o conhecimento inscrito na 
atividade do operador que vai orientar e guiar a ação até o seu resultado (Samurçay e Pastré, 2004).

Desse debate vem a insistência sobre a noção de situação: em formação profissional, não são os saberes científicos que vêm em primeiro lugar, são os das situações de trabalho, complexas e carregadas de variabilidade. É a partir da situação na qual se encontra o operador que ele vai organizar sua ação e mobilizar eficazmente certo número de conhecimentos. Segundo Pierre Pastré (2006), a análise da situação permitirá encontrar os caminhos de seu controle, o que é o objetivo de uma formação profissional. Uma situação de trabalho bem compreendida é uma situação que se pode racionalizar, transpor, simular.

A constatação da impossibilidade subjacente àquele que realiza a ação inteligente no trabalho - impossibilidade de pensar integralmente a situação antecipadamente - é uma herança da ergonomia. A originalidade da ergologia começa sem dúvida aí, em torno desse pivô, que é a reflexão localizada no fazer. Do ponto de vista da ergologia, pensar na ação não é somente uma obrigação saída do meio, é também um imperativo de saúde. Encontramos aqui a dupla leitura: atividade intelectual e atividade vital. O esforço de conhecer é também um esforço de viver.

Quando um meio de trabalho pretende lhe impor integralmente suas próprias normas, o ser humano adoece ou se revolta: ele não pode se determinar a ser apenas uma engrenagem numa máquina. A consígnia estrita 'faça unicamente o que lhe digo' será para ele impossível de viver, insuportável, desconstruirá toda a sua motivação e afetará dolorosamente sua saúde. "Uma reação forçada é uma reação patológica", observou Canguilhem (1947, p. 125) àqueles que esperavam submeter a força de trabalho somente à lógica das organizações industriais. As pessoas não estão diante de uma simples necessidade, mas diante de uma dupla necessidade de refletir ao agir - isso é um fato fundamental, característico de nossa humanidade e gerador de história. Uma necessidade reforça a outra - e essa interação acarreta inelutavelmente a modificação dos dados iniciais. Necessidade de pensar ao agir, sendo o ator da mudança (obrigação saída do meio); mas necessidade redobrada de pensar agindo, sendo autor da mudança (imperativo de saúde: viver no centro da decisão de agir). O fenômeno de uma reprodução idêntica continuamente impedida - fenômeno motor de história - é descrito por Yves Schwartz como uma dialética, aquela do impossível e não vivível.

Para agir num mundo onde a antecipação total (a padronização) é impossível, é necessário alguém capaz de fazer uso de si - para gerir o que não foi pensado antecipadamente. O ser humano em atividade não cessa de renormalizar, de arbitrar diante do furo de normas ou da inadaptação e da rigidez das normas antecedentes. Agindo isso, ele somente faz aumentar a variabilidade da situação inicial, 
distanciando cada vez mais da perspectiva - invivível - da padronização. Ele produz assim a singularidade, a história, via as renormalizações (Schwartz e Durrive, 2009, p. 256).

Parece-nos que podemos avançar na hipótese seguinte: o projeto da didática profissional é explorar todas as dimensões conceituais da atividade de trabalho de um operador. A perspectiva ergológica abarca esta preocupação a partir da constatação da impossibilidade de padronização da situação produtiva, mas ela indica ainda outra dimensão do agir profissional, visualizando a hipótese da padronização, dessa vez do lado do protagonista. É a característica potencialmente 'invivível' de uma total antecipação que leva o operador a tentar obstinadamente ficar no centro do que ele decide fazer. Isso implica reforçar que a subjetividade no trabalho de que falamos não é um componente como outros: é na realidade a própria atividade, indissoluvelmente atividade intelectual e atividade vital. Uma curta reflexão sobre o agir competente ou competência permitirá clarear este último ponto.

Para abordar o agir competente levando em conta os ensinamentos da análise da atividade, Yves Schwartz propõe uma analogia com os ingredientes. O mal-entendido seria imaginar uma coleção de elementos separados que comporia um agir individual tal como um patchwork. Oposto a tal representação fragmentada do agir individual, os ingredientes da competência levam em consideração uma unidade que não exclui os heterogêneos. Certamente existe um só agir, uma só instância ou corpo-si, que se engaja no mundo para fazer algo, graças a diferentes aportes. O primeiro ingrediente nos remete ao epistêmico: é o relativo domínio que uma pessoa pode ter dos saberes do métier ou da organização, dados numéricos, protocolos diversos etc. relacionados à tarefa a cumprir. O segundo ingrediente corresponde à preocupação ergológica: é o relativo domínio que essa mesma pessoa tem para enfrentar o meio no qual ela se encontra, submetida a incessantes transformações, por uma parte não antecipáveis, um meio inscrito numa história local, com as heranças locais mais ou menos explícitas. O terceiro ingrediente da competência é crucial, porque se trata da relação entre os dois precedentes: a inteligência da ação aqui e agora.

Podemos afirmar que em nenhuma situação de trabalho o operador neutraliza esses três ingredientes de base. Resolver um problema na situação, hic et nunc, é a característica do trabalho em geral. Pierre Pastré (2006, p. 120) escreve: "no trabalho, os problemas são cada vez mais raros". Mas ele acrescenta: "Ou cada vez mais significa dizer que fazemos de tudo para erradicá-los: estabelecimento de procedimentos, formação, mudanças na organização do trabalho. Entretanto, não conseguimos suprimi-los". Em outro momento, ele utiliza o termo 'problema' como sinônimo de desfuncionamento. Mas podemos voltar ao significado mais antigo dessa palavra, que se 
aproxima dos usos que fazemos na matemática: uma questão que pede uma resposta, uma solução. O trabalho aparece, então, como uma sequência indefinida de problemas a resolver, no sentido dos ingredientes que acabamos de descrever. Jamais a situação local é padronizada a ponto de não mais exigir algum nível de reflexão do operador. Isto foi demonstrado pelos ergonomistas há muito tempo, a partir dos postos mais taylorizados da indústria (Schwartz e Durrive, 2003).

A didática profissional reflete sobre as situações-problema de maneira a (re)ativar no aprendiz a dialética agir e compreender, em que o modelo operativo e o modelo cognitivo se reforçam mutuamente na atividade. Ela vai aprofundar o que acabamos de chamar ingrediente três da competência, uma forma de renormalização, analisando a atividade do protagonista confrontada à tensão entre constantes e variáveis na situação encontrada, uma atividade que se organiza graças a esquemas, capazes ao mesmo tempo de antecipar, por esquemas de ação, as solicitações do meio, e de reagir se ajustando às circunstâncias.

Lá, ainda, a perspectiva ergológica encontra a didática profissional que destaca a dimensão antropológica da atividade humana: esta é simultaneamente produtiva e construtiva. A atividade é orientada para os outros, a serviço dos outros, mas ao mesmo tempo é voltada para a construção identitária.

O homem é esse ser que sabe extrair algo de sua atividade e incluir na sua identidade, na medida em que esta perdura. Ora, em toda a atividade humana há sempre duas faces, uma atividade produtiva, que é a transformação do real, e uma atividade construtiva, que é a transformação de si graças à sua própria prática. Atividade produtiva e atividade construtiva não são dissociáveis: não há atividade que não comporte, mesmo que minimamente, uma parte de aprendizagem (Rabardel e Pastré, 2009, p. 232).

A ergologia vai, entretanto, além da didática profissional na análise da dimensão antropológica do agir. Ela descreve três ingredientes suplementares da competência, justamente buscando considerar a profunda unidade do agir humano, em referência à dupla atividade intelectual e vital. De imediato, convém insistir sobre a característica recorrente desses novos ingredientes: eles não se justapõem aos três precedentes, mas retornam a eles permanentemente, investem sobre eles, definindo para além a qualidade do agir individual (e mostrando mais uma vez que a subjetividade, no fundo, é a atividade). O esforço de viver reencontra o esforço de conhecer, ele se potencializa a fim de lhe transmitir sua energia e multiplicar assim suas possibilidades. Inversamente, se o esforço de conhecer é desconectado do esforço de viver - e é, nos parece, o caso de um aluno em situação de fracasso escolar, em que o drama é ter perdido a ligação entre os dois -, então, os três 
primeiros ingredientes correm o risco de se degradarem, de se desvitalizarem, e a pessoa nesse caso diminui a capacidade de desenvolver competências.

Os ingredientes suplementares descritos por Yves Schwartz são os seguintes. O quarto ingrediente designa o debate ao qual não escapa quem vai agir, porque ele não é um autômato. Há necessariamente um ponto de vista sobre o uso dele mesmo que lhe convém, para colocar em debate com a solicitação de outro, em relação com os valores. Existirá, sim ou não, mais ou menos, convergência com o que é importante no caso presente? A resposta seria: o grau de investimento no terceiro ingrediente, a qualidade das renormalizações, pode variar consideravelmente. O quinto ingrediente está diretamente ligado ao grau de adesão derivado do ingrediente quatro. Trata-se de mobilizar o potencial da própria pessoa, a parte de si mesmo que se coloca na realização do procedimento - anônimo de início - e que envolve a qualidade do agir por inteiro. Por fim, há o sexto ingrediente, posto no fim da lista, mas em realidade representando a origem e o resultado de tudo o que operador realiza: a qualidade das interações, as sinergias coletivas, a ligação com os outros - essa ligação que dá um sentido global ao agir individual.

Para a didática profissional e para a ergologia, a atividade humana é uma fonte rica de saberes. ${ }^{7}$ Porque elas compartilham um ponto de vista antropológico sobre o processo de conhecer, as duas abordagens reconhecem dois registros de conceitualização, decorrentes de duas formas de conhecimento. Esses dois registros são como tecidos, imbricados a tal ponto que Vergnaud (1996, p. 276) escreve: “a maior parte de nossos conhecimentos são competências". Nós pensamos que isso tem a mesma natureza da atividade humana, que é ao mesmo tempo intelectual e vital. A ação - o agir - é um momento de renormalização, desde que se considerem os debates de normas. Dito de outra forma, um momento de arbitragem da vida e simultaneamente de conceitualização. Nesse processo complexo, nos parece que a didática profissional visualiza a atividade mais do ângulo intelectual, enquanto a ergologia a concebe prioritariamente do seu ângulo vital. As duas abordagens se justificam e são, a nosso ver, complementares.

\section{Uma perspectiva de tradução da complementaridade entre a didática profissional e a ergologia: a formação alternada}

Nos dispositivos de inserção profissional, a experiência em empresa tem um papel em primeiro plano. Entretanto, sabemos que os estagiários e os aprendizes na fase inicial de formação têm muita dificuldade de gerir a alternância entre a teoria e prática. Desenvolvemos há vários anos, com a criação dos dispositivos públicos de inserção-formação, entrevistas sobre a atividade de reflexão sobre a experiência vivida nas empresas. ${ }^{8}$ A metodologia se apoia no 
quadro teórico da ergologia. Esse tipo de entrevista conforta a pessoa na tomada de consciência do "uso de si" (Schwartz, 1992), revelando as condições em que os constrangimentos se tornam recursos. A singularidade da experiência aparece graças a uma aproximação com as arbitragens em situação e, simultaneamente, a uma tomada de distância em relação às escolhas efetuadas. Evidenciar algumas conexões favorece novas significações, como se a experiência vivida adquirisse um novo volume. O aprendiz é então reposicionado, passando pela análise de sua própria atividade: nessas condições a dimensão teórica da sua formação pode lhe aparecer com outro olhar.

Levantamos, no entanto, a hipótese de que falta intermediação entre a atividade de trabalho, assim revisitada, e o aporte teórico de um ensinamento: é a análise da prática segundo a didática profissional. A ergologia permitiria reconhecer aquilo que diz respeito ao serviço na situação de trabalho, e a tarefa específica seria mais bem abordada e analisada pela didática profissional de forma a compreender, ao mesmo tempo, o circuito curto de um modelo operativo e o circuito longo de um modelo cognitivo que o sustenta.

Entretanto, percorremos até aqui só uma parte do caminho. Os dispositivos públicos de formação profissional são compartimentalizados, as etapas de mobilização e de qualificação estão confiadas a operadores diferentes. É por isso que as entrevistas que comentamos aqui, realizadas na fase inicial - não qualificante, dita de mobilização -, não são retomadas mais tarde no percurso, quando da preparação para o métier. É lamentável porque se o métier é definido pelo controle das tarefas, percebe-se, porém, que o processo de qualificação pode começar bem antes que os conceitos sejam controlados. Mas isso supõe reconhecer a atividade em face da tarefa. A vida no trabalho, desde que ela se torne reflexiva, é uma poderosa alavanca de formação.

Uma formação em alternância se apoiando sobre duas abordagens precisa ainda ser construída. Entretanto, dispomos de exemplos promissores. $\mathrm{O}$ de Marc, um jovem operador em meio industrial, ${ }^{9}$ pode ser evocado - mesmo não havendo espaço aqui para explicar o caso em detalhes - porque ele tem a vantagem de se situar num contexto de máquinas injetoras de plástico líquido em moldes. Nesse tipo de situação de trabalho, tendo servido às primeiras construções teóricas da didática profissional, pode-se fazer sem dificuldade a ligação entre uma entrevista explorando a vida no trabalho e investigações mais aprofundadas que tratam da atividade intelectual do operador. Como não desenvolveremos outro exemplo, daremos alguns elementos metodológicos sobre a entrevista de tipo ergológico.

Em que condições podemos formar a partir do trabalho? A experiência não é automaticamente formadora. Para que haja ampliação, enriquecimento do que se sabe, é necessário - para retomar uma fórmula de Yves Schwartz "distinguir a experiência do trabalho e o trabalho como experiência". Pensar o trabalho como experiência é reconhecer que ele é sempre "gestão 
do aspecto normas antecedentes e do aspecto encontro do encontro". (Schwartz, 2004). O primeiro aspecto corresponde a tudo que estrutura antecipadamente uma situação de trabalho e permite antecipar a maneira de fazer a tarefa a ser realizada. O segundo aspecto leva em conta o fato de uma situação ser singular porque ela é feita de trajetórias que se entrecruzam: uma pessoa que tem uma história encontra uma máquina que tem uma história...

O nosso interesse é perceber melhor a singularidade da experiência individual, o que destaca, pelo contraste, os saberes gerais operando na situação de trabalho. Distinguir o específico do geral nos parece ser uma etapa na tomada de consciência do trabalho como experiência, como diálogo, ou ainda como dialética entre os saberes formais e os saberes investidos na atividade.

Nossas entrevistas apoiam-se sobre a distinção entre tarefa e serviço, seguindo uma metodologia baseada na temporalidade: balizamento do que precede a atividade, depois ancoragem no momento dessa atividade. O trabalho implica realizar uma tarefa: é o registro das normas que a ergologia qualifica de antecedentes (na medida em que outras normas são produzidas na atividade). Mas isso não é tudo: trata-se de realizar uma tarefa na configuração de um serviço - e esse último está ainda mais submetido às variabilidades do que a própria tarefa. A tarefa antecipa o serviço a fazer, porque a situação de trabalho é organizada para isso - mas de qualquer forma o serviço antecipará por sua vez a tarefa, na medida em que, mesmo em proporções ínfimas, o serviço reconfigura a cada momento a tarefa de tal forma que ela é padronizada (Schwartz e Durrive, 2009). Reconhecemos aí o que Yves Schwartz chama de "dupla antecipação" que caracteriza a relação entre a experiência e os saberes formais.

Um retorno à experiência segundo a ergologia facilita, para a pessoa implicada, a tomada de consciência de seu papel singular no fazer, ampliando a percepção do que ela deve gerir de específico na situação para colocar em prática a tarefa que ela se define no geral. A experiência do trabalho real, densa e complexa, esclarece-se para ela progressivamente. Novas significações vão surgindo a partir dessas relações que se estabelecem.

\section{Conclusão}

Nas situações de formação alternada, pode-se pensar que a experiência, estando mais bem controlada graças à atividade colocada em palavras segundo a ergologia, poderia agora ser articulada com os ensinamentos correspondentes. Levantamos, entretanto, a hipótese de que, entre a atividade entendida como um debate de normas ligado a um mundo de valores (Schwartz e Durrive, 2009) e o curso teórico, falta uma mediação, a da prática, analisada pela didática profissional. 
A oposição epistêmico/ergológico permite conceber a experiência - a da pessoa que trabalha - como uma dupla antecipação, no sentido dado anteriormente: o esforço de conhecimento tende para o epistêmico quando ele visa à generalização, à neutralização do local para identificar os saberes, regras e organização operantes. Inversamente, o esforço de conhecimento tende para o ergológico quando ele procura desneutralizar, se aproximar dos debates de normas, das microarbitragens em situação.

Além disso, a oposição epistêmico/pragmático permite entender a experiência como uma modalidade de articulação entre o cognitivo e o operativo. Ao focalizar um problema presente na situação de trabalho, transformamos esse problema em uma situação de aprendizagem intencional. No registro pragmático de conceitualização, levamos a pessoa a saber como agir e, no registro epistêmico de conceitualização, levamos a se apropriar do saber que lhe permitirá tratar seu problema.

Em decorrência da entrevista sobre a atividade segundo a abordagem ergológica, as circunstâncias que conduziram a pessoa a fazer certo número de arbitragens em situação de trabalho são um pouco mais bem conhecidas. A dimensão de serviço inerente à situação dada é mais bem controlada, o que é possível após focalizar sobre a tarefa e sua aprendizagem contextualizada, segundo a didática profissional. Passamos de um 'meio de vida' no trabalho, no sentido de Georges Canguilhem, a um 'meio suporte de aprendizagem', no sentido de Pierre Pastré (2006), articulando a aprendizagem de uma atividade em situação e a aprendizagem de um saber.

\section{Notas}

1 Professor associado do Laboratório Interuniversitário de Ciências, da Educação e da Comunicação (Lisec), da Faculdade de Ciências da Educação de Estrasburgo, França. Doutor em Ciências da Educação pela Universidade de Estrasburgo. <louis.durrive@unistra.fr> Correspondência: Laboratoire Interuniversitaire des Sciences de l'Education et de la Communication, 7 rue de l'Université, 67000, Strasbourg, France.

2 “Pensar, é viver no sentido. O sentido não da relação entre (...), é na relação com” (Canguilhem, 1992b, p. 27).

3 Yves Schwartz em entrevista com o autor (dezembro de 2007).

4 Dramática de uso de si: originalmente, um drama - individual e coletivo - ocorre quando eventos surgem, rompendo o ritmo de sequências habituais, antecipáveis, da vida. De onde vem a necessidade de reagir, no sentido de gerir esses eventos, fazer uso de si. Ao mesmo tempo, isso produz novos eventos, que transformam a relação com o meio e com as 
pessoas. A situação é então matriz de variabilidade, matriz de história, porque ela engendra alguém diferente, por causa das escolhas a fazer (microescolhas) para gerir os eventos. Então a atividade aparece como uma tensão, uma dramática (Schwartz e Durrive, 2009).

5 Para ser mais preciso, a disciplina epistêmica, segundo Schwartz, demanda que distingamos os níveis de conceitualização (epistemicidade): essa disciplina visa a encontrar ou produzir uma arquitetura conceitual, seja no campo epistêmico (onde os objetos não têm debate de normas), seja no campo ergológico (onde há o debate de normas).

6 Excentrement e recentrement são conceitos utilizados por Yves Schwartz para falar da complexidade do processo de renormalização do ser humano em relação ao seu meio de vida.

7 Destacamos aqui duas opções terminológicas. No vocabulário ergológico, um saber é ligado às renormalizações: mais ou menos em aderência, portanto, singular, mais ou menos próximo da conceitualização, diferente do conhecimento, que corresponde às construções intelectuais elaboradas em desaderência. Ao contrário, Pastré parece preferir uma definição de saber como o que é constituído e validado fora da atividade, enquanto o conhecimento é para ele inscrito nessa atividade, a fim de orientá-la e guiá-la.

8 Ver um exemplo de entrevista em Durrive (1999).

${ }_{9}$ Exemplo desenvolvido na nossa tese (Durrive, 2006, p. 161-172).

* Este artigo foi traduzido, do original francês, por Magda Duarte dos Anjos Scherer, professora do Departamento de Saúde Coletiva da Universidade de Brasília.

\section{Referências}

CANGUILHEM, Georges. Milieu et normes de l'homme au travail. Cahiers Internationaux de Sociologie, Paris, v. 3, p. 120-136, 1947.

DELLA VALLE, Fulvio. La connaissance de la vie [1965]. Paris: Vrin, 1992a.

Le cerveau et la pensée. In: COLLEGE INTERNATIONAL DE PHILOSOPHIE (Dir.). Georges Canguilhem philosophe, historien des sciences. Paris: Albin Michel, 1992b. p. 11-33.

Etudes d'histoire et de philosophie des sciences [1968]. Paris: Vrin, 1994.

. Le normal et le pathologique [1966]

Paris: PUF, 1999.
.Normatif. In: ZARA-DER, Jean Pierre (Dir.). Dictionnaire de phi-losophie. Paris: Ellipses Éditions, 2007.

DURRIVE, Louis. Une action de formation en milieu carcéral. In: J. DOLZ, Joaquim; OLLAGNIER, Edmée (Dir.). L'énigme de la compétence en éducation. Bruxelles: De Boeck Université, 1999. p. 169-182.

L'expérience des normes: formation, éducation et activité humaine. Lille: ANRT, 2006.

LE BLANC, Guillaume. La vie humaine: anthropologie et biologie chez Georges Canguilhem. Paris: PUF, 2002. 
PASTRÉ, Pierre. La conceptualisation dans l'action: bilan et nouvelles perspectives. Education Permanente, Paris, n. 139, p. 1336, 1999.

Apprendre à faire. In: BOURGEOIS, Etienne; CHAPELLE, Gaëtane (Dir.). Apprendre et faire apprendre. Paris: PUF, 2006. p. 109-121.

RABARDEL, Pierre; PASTRÉ, Pierre. (Dir.). Modèles du sujet pour la conception: dialectiques activités développement. Toulouse: Octarès Éditions, 2009.

SAMURÇAY, Renan; PASTRÉ, Pierre. (Dir.). Recherches en didactique professionnelle. Toulouse: Octarès Éditions, 2004.

SCHWARTZ, Yves. Travail et philosophie: convocations mutuelles. Toulouse: Octarès Éditions, 1992.

. Discipline épistémique, discipline ergologique: paideia et politeia. In: MAGGI, Bruno (Dir.). Manières de penser, manières d'agir en éducation et en formation. Paris: PUF, 2000a. p. 126-149.

Le paradigme ergologique ou un métier de philosophe. Toulouse: Octarès Éditions, 2000b.
L'expérience est-elle formatrice? Education Permanente, Paris, n. 158, p. 1123, 2004.

L'activité. Laboreal, Porto, v. 1, n. 1, p. 63-64, 2005. Disponível em: $<$ http://laboreal.up.pt/media/artigos/40/10 Yves PT.pdf $>$.

Produire des savoirs entre adhérence et désadhérence. In: BÉGUIN, Pascal; CERF, Marianne (Dir.). Dynamique des savoirs, dynamique des changements. Toulouse: Octarès Éditions, 2009. p. 15-28.

SCHWARTZ, Yves; DURRIVE, Louis. (Dir.). Travail et ergologie: entretiens sur l'activité humaine. Toulouse: Octarès Éditions, 2003.

(Dir). L'activité en dialogues suivi de manifeste pour un ergo-engagement. Toulouse: Octarès Éditions, 2009.

VERGNAUD, Gérard. Au fond de l'action, la conceptualisation. In: BARBIER, JeanMarie (Dir.). Savoirs théoriques et savoirs d'action. Paris: PUF, 1996. p. 275-292.

WISNER, Alain. Réflexions sur l'ergonomie: 1962-1995. Toulouse: Octarès Éditions, 1995. 